\title{
LEARNING IN DYNAMIC INTER-FIRM NETWORKS - THE EFFICACY OF MULTIPLE CONTACTS
}

\author{
JOHN HAGEDOORN* and GEERT DUYSTERS**
}

August 1999

The US National Science Foundation funded this research in part. Portions of this study were undertaken when Hagedoorn was a visiting scholar at the Center for Economic Policy Research at Stanford University and the Haas School of Business of the University of California at Berkeley. The authors thank participants at seminars at Maastricht University, Utrecht University, University of California at Berkeley and University of British Columbia comments on a preliminary version of this paper.

*MERIT, Faculty of Economics and Business Administration, Maastricht University, P.O. Box 616, 6200 MD Maastricht, The Netherlands - telephone (31)43-3883897 - fax: (31)43-3216518 - e-mail: j.hagedoorn@mw.unimaas.nl

**ECIS, Faculty of Technology Management, Technological University Eindhoven, The Netherlands - e-mail: G.M. Duysters@tm.tue.nl 


\section{LEARNING IN DYNAMIC INTER-FIRM NETWORKS - THE EFFICACY OF MULTIPLE CONTACTS}

This paper examines the relevance of both an efficiency-based network strategy and a learningbased network strategy in the context of inter-firm partnering. The effect of these different forms of network behaviour on company performance is analysed for companies in the international computer industry. Strategies associated with learning through so-called exploratory networks appear to generate a greater impact on technological performance in a dynamic environment than efficiency strategies through exploitative networks.

(Networks, learning, technological performance) 


\section{INTRODUCTION}

The objective of this paper is to evaluate different network strategies that can guide companies in setting up network-ties with other companies through which they gain access to information that enables them to achieve higher performance than other network players. This particular perspective follows some recent developments in academic work on networks (Burt 1992a and b; Freeman, 1979; Powell, Koput and Smith-Doerr, 1996; Walker, Kogut and Shan, 1997) where the attention paid to the strategic behaviour of network players coincides with a refocusing of research from the traditional laboratory setting or a purely theoretical approach to empirical research. This increase of empirical network analysis particularly affects the current management and organization literature that focuses on the effect of both intra- and intercompany networks on company performance. According to some, the practical and strategic implications of recent empirical network analysis might even go as far as offering "... a manual for those wishing to optimize their instrumental networks ..." (Andrews, 1995, p. 355) in a concrete business setting.

In the following we will refer to two different network analytical approaches where either efficiency or learning is placed in the context of strategic players who are using networks in which they operate to improve their own performance vis à vis other players. The expected higher performance of strategic players, then, is linked to their ability to access information about rewarding opportunities, applying a network strategy that is based on either maximum efficiency in setting up network-ties or based on learning through multiple contacts with a number of companies. ${ }^{1}$

One of the practical implications of our critical evaluation of modern network analysis 
is that we will qualify some of its instrumentalist and concrete suggestions. In our opinion, concrete advice based on applied network analysis in a market environment can easily lead to some misleading suggestions for the network strategies of companies, unless proper attention is paid to the environmental and behavioural conditions of networks. The main point we are making below is that in a dynamic environment, efficiency behaviour, which might pay off in a static environment, will lose its purpose. Strict maximizing rules for the efficiency of networks, for instance with a preference for so-called non-redundant contacts, might be rational in a static environment, but learning through multiple contacts, with some quasi-redundancy, will be more effective in a dynamic environment. This discussion of different forms of rationality in network strategies, that we refer to as efficiency or exploitative network strategies versus learning or exploratory network strategies, returns to the classical discussion on the role of improved information flows through increasing contacts that come with higher 'gregariousness' (Erbe, 1962). Under conditions of increased gregariousness, which implies an increasing number of contacts between participants, the flow of information also increases. This approach emphasizes improved information flows through repeated ties with a number of partners instead of efficiency improvement by means of non-redundant contacts.

Following suggestions by among others Burkhardt and Brass (1990), this paper focuses on the level of inter-organizational networks, more in particular on companies, their interrelationships, and their performance in terms of their learning achievements through networks. Traditionally network analysis was mainly applied to study inter-personal networks. Recent contributions to the study of inter-organizational relationships have introduced a network perspective, using standard network measures, to understand the development of groups of 
companies and individual companies in a competitive environment. Comparing different forms of networking behaviour, we complement this recent research in which the diversity in the network portfolio of companies, through their range of ties to other companies, is placed in the centre of empirical research (Burt, 1992a and b; Duysters and Vanhaverbeke, 1996; Gulati, 1995a; Mowery, Oxley and Silverman, 1997; Powell et al, 1996; Walker et al, 1997; Zaheer and Zaheer, 1997). More specifically, we will analyse inter-firm networks of strategic technology alliances through which companies acquire R\&D-related knowledge that will help them differentiate their technological performance from other companies.

In the next section, we first explore the theoretical background of network analysis from both an efficiency and a learning perspective, leading to the basic hypothesis to be tested in this paper. In the following section we explain the general model and the set of variables used in this study and we report on the data set and the population of companies that is studied. We chose the international computer industry to analyse the effect of different network strategies on the technological performance of companies. After we report on the results of our investigation, we discuss our findings and draw conclusions in terms of the implications of different network strategies for learning and technological performance of companies.

\section{THEORETICAL PERSPECTIVES ON INTER-FIRM NETWORKS}

\section{An efficiency perspective on networks}

Social network analysis has been developed through various models using laboratory settings, scenarios and small number experiments. Many of these models feature some rather strong, assumptions about the efficiency of maximizing behaviour by network players. These 
assumptions show a remarkable resemblance to the economic 'textbook' maximizing understanding of economic subjects with perfect knowledge and complete information about market transactions. ${ }^{2}$ Translated to companies and their networks, such 'textbook' examples of maximizing assumptions still found in much of the current social network analysis (see for instance, Leik, 1992) are:

- $\quad$ companies (players) in a network setting are expected to have complete and accurate information about all network linkages

companies comprehend and apply the principles of network power, which implies that they are very selective and efficient in choosing partners.

Given these maximizing or efficiency assumptions, simply increasing the number of 'dyadic' linkages within an existing network is not necessarily rational or valuable. Being linked to companies that carry interesting information and that play a crucial role in an overall set of network-linkages is seen to be more valuable than just being part of a dense network. In other words, there is diminishing utility of added linkages in general, whereas there is an increasing utility for adding the 'right' kind of linkages. Based on such behavioural assumptions, the distribution of network linkages among different companies implies that participants with low network participation will prefer to add new links to their existing network, whereas central players choose to delete as many duplicating links as possible. Linking up to well-positioned companies with a high 'network status' is also thought to be more valuable than just being linked to others in a network of whatever density. This strategic manipulation of network linkages, through which major players change the potential of their position, is a crucial element in more recent contributions to network power theory (Leik, 1992). 
In organization and management related studies of networks, the current developments in network theory have stimulated a further search and demand for improved network analysis that should go beyond a straightforward evaluation of network positioning (Salancik, 1995). Apart from theoretical research on the implications of different network structures for the interactions within networks, empirical research related to recent developments in network theory concentrates on the individual company perspective with some network positions generating better access to information and better results with fewer constraints than others.

The recent work by Burt (1992 a, b) is one of the more influential contributions, which is also a good example of the current efficiency approach in network analysis. Central to this approach is the already well accepted idea in 'traditional' network analysis that the size of a specific network of a strategic player as such is not that important. What really counts is the number of non-redundant contacts, because it is assumed that redundant contacts carry the same information. By definition, dense networks involve a considerable degree of interaction between companies and many of these interactions are expected to be redundant and inefficient.

The argument is taken further by stressing that strategic players (companies) should aim at having non-redundant contacts or 'structural holes' that are additive and not merely overlapping. A strategic player can create an efficient network by focussing resources on the maintenance of 'bridge ties' that overarch structural holes with as little redundancy as possible. In standard network analysis terminology this implies that the structural equivalence of strategic players in the network (the degree of interaction with the same players) and the cohesion in strategic players' networks (the connectivity of players) should be limited to benefit from their contacts. In addition, linking up to other players that have a high degree of network status, as 
they are well positioned in the network, is important for the transfer of information.

In terms of the current social network terminology, implications of an efficiency framework for understanding the benefits for strategic players are as follows:

- $\quad$ it is beneficial for companies to get access to existing information through a limited number of diverse contacts (bridges), avoiding dense inefficient networks

- $\quad$ companies should also avoid duplication of existing contacts; however, they should create well-informed and selective linkages that generate so-called structural autonomy and that exercise control over rewarding opportunities (structural equivalence should be small)

- $\quad$ having access to information and being linked to others with high network status makes a company a suitable partner for others (network status should be high). ${ }^{3}$

\section{A learning perspective on networks}

An alternative approach for understanding network strategy, that we would like to present, assumes that companies experiment with and learn from their contacts without following strict rules of efficiency maximization. ${ }^{4}$ This approach parallels some of the work in evolutionary economics that stresses the positive effect of learning behaviour on company performance in a dynamic context. For instance, Silverberg and Verspagen (1994 and 1996) found that in a world of technological change firms do not necessarily demonstrate short-term optimal, efficient behaviour, instead a long-term, learning-oriented behaviour was found to generate higher returns. The analysis of Allen (1988) also shows that in a dynamic economic environment, learning through various contacts pays off as this behaviour can outperform short-term maximizing behaviour that concentrates on the efficiency in existing contacts. This attention 
paid to the importance of learning, particularly in a dynamic, technologically sophisticated, environment returns in a growing body of literature on alliances, learning and industry development (e.g. Ciborra, 1991; Osborn and Hagedoorn, 1997; Oster, 1992; Powell et al, 1996).

Also, the more general literature on the learning behaviour of companies (and individuals) reveals that a dynamic environment with changing conditions encourages continuous learning by companies. Environmental change and exposure to new ideas is expected to extend the existing knowledge base of companies, improve their existing learning capabilities and, more in particular, improve their technological capabilities (Cohen and Levinthal, 1989; March, 1991). As suggested by, amongst others, Barkema and Vermeulen (1998) cooperation between companies in changing environments helps companies to learn different ways of doing things, generates new ideas and new practices creating incentives for innovative behaviour that further enhances their technological capabilities.

To continue along this line of argument we suggest that in a dynamic environment, for instance due to technological development or market structural changes, the relevance of continuous learning by companies increases. In case of technological change, for instance with a switch of technological trajectories with new basic designs (Dosi et al, 1988), there is immanent uncertainty about future technological development. It will be hard for companies to assess which company or group of companies will be the first to master and develop new technologies or who will be the main carriers of new innovations. This lack of clarity regarding the role of major players seems in particular present in advanced sectors where new designs are frequently developed by new players (Wade, 1996). Research so far also suggests that with the 
introduction of new basic designs, these new designs foster new market niches occupied by a mixture of older companies and new companies, where the role of new players remains somewhat unclear for some time (Dosi et al, 1988; Duysters, 1996, Hagedoorn, 1989; Sahal, 1981). Concentrating only on those companies that can provide information on existing, fully developed technologies, through their central network position and their 'bridges' to other established networks, might miss unexpected opportunities. Entering into a relationship with a well-established player with a high network status and technological credibility is important for the transfer of established knowledge but this is not necessarily relevant in the quest for new knowledge that is central to new technological developments.

This kind of argument also applies to market structural change where entry, from either new companies, international competitors or diversifying companies, can change the competitive space for particular companies or a group of companies, in a similar way as changes due to technological development. In some recent contributions to network theory, the implications of open systems for the perception of efficiency in networks with entry of new players are recognized. For instance, Yamaguchi (1994) acknowledges that with open systems there are increasing flows of 'across boundary information'. Due to environmental changes, the focus on the efficiency of information processing, building bridges in existing networks and avoiding duplication of contacts, will become less relevant. Consequently, the attention will shift towards the effect of environmental transformation on changing configurations of networks of companies.

For a learning strategy in the context of inter-firm networks in an environment of technological change it seems much more important that companies build a relationship with 
various players with whom they can jointly develop new technological knowledge. A number of studies reveal that multiple contacts over a number of years can help companies build interorganizational trust (Gulati, 1995b; Heide and Miner, 1992; Kogut, 1989; Nooteboom, Berger and Noorderhaven, 1997; Saxton, 1997). This literature suggests that shared experiences with several contacts encourage companies to add new dimensions to their collaboration. Joint technological development can certainly be seen as an important aspect of further collaboration between companies, which also exposes the partners to new ideas, enhances their innovative behaviour and improves their technological capabilities. We expect that having a multitude of repeated alliances with various partners, without permanent concern regarding the efficiency of their overall network relationships, helps to build trust among these companies.

The argument we are making boils down to the following: efficiency behaviour could be appropriate in a static environment but in a dynamic environment, characterized by technological change and 'openness' of markets, continuous learning, even through seemingly redundant contacts is to be preferred. Dynamic environments also request more as to intensive, exploratory learning (Dodgson, 1993; March, 1991) for which companies can use a diversity of links to particular companies without maximizing the efficiency of their overall network-ties. In a dynamic environment, the current network status of companies is not an accurate predictor of their potential future influence and the network itself is fluctuating such that even the set of potential partners is not clearly defined. Following a learning-based strategy implies that under conditions of change the value of a particular tie or a number of ties, between players might be unknown or difficult to estimate at the start of the collaboration. In searching for valuable contacts, redundancy reduction is not a priority if companies intend to learn from a variety of 
sources through the network in which they are operating. For instance, Gomes-Casseres (1996) points at the positive effect that the intentional duplication of contacts between participants in networks might have for improving their learning capabilities. Over time, a successful tie-up might develop information that was unknown at its initial stage. The value of the information and the value of the process of exploratory learning that goes with establishing different tie-ups to other companies cannot be estimated beforehand. Also, a company's exact network pattern that would generate the highest returns is not to be known in advance.

Based on the above, we can formulate one basic hypothesis that will guide our research: In a dynamic environment, a learning-based network strategy generates higher, positive effects on the performance of companies than an efficiency-based network strategy.

\section{METHODOLOGY AND DATA}

\section{Population}

In the following we will study the different effects of efficiency and learning on company performance in the context of networks of strategic technology alliances, with joint R\&D and other shared innovative efforts. These strategic technology alliances, through which companies acquire R\&D-related knowledge, are expected to help them differentiate their technological performance from other companies. The relevance of this topic, as for instance demonstrated by the growing importance of strategic technology alliances as a major element in the external linkages of companies, has been documented in many publications. See Hagedoorn (1996) and Osborn and Hagedoorn (1997) for an overview of the literature.

Given the emphasis on 'technology' alliances the effect of these alliances will be related 
to the technological performance of companies and not to economic performance in general. However, this technological performance of companies is expected to be not only dependent on the networking characteristics of companies but also to be dependent on some firm specific characteristics or endogenous capabilities. In that context one has to think of the size of companies that captures scale and scope effects and R\&D efforts that might generate technological performance differentials.

Our empirical analysis covers the industrial, technological and networking activity of companies operating in the international computer industry. There are 88 companies in our analysis (see Annex II), these companies represent over $80 \%$ of the sales of the worldwide computer industry. There are several reasons for choosing this particular industry and its network of strategic technology alliances. The computer industry is known to be a high-tech sector that creates a dynamic environment for companies (OECD, 1992). It is a large, competitive and technologically advanced sector with a high R\&D intensity of over $10 \%$ (OECD, 1997). It is an industry where one finds a large number of strategic technology alliances that play an important role in the competitive strategies of companies (see amongst others, Duysters and Hagedoorn, 1998; Gomes-Casseres, 1996; Hagedoorn and Schakenraad, 1992; Mytelka,1991). It is also a sector with a diverse population of companies such as diversified companies, specialized suppliers, new entrants and 'older' established companies (Duysters, 1996; Duysters and Hagedoorn, 1995; Gartner Group, 1994).

\section{Dependent variable}

In this study, technological performance is measured by taking the 1993 patent intensity of companies, i.e. the number of computer patents divided by the size (computer revenues) of the 
company, as the innovative output indicator. As so many other measures this patent indicator is subject to a debate regarding its usefulness (Cohen and Levin, 1989; Griliches, 1990; Archibugi, 1992). However, it may be one of the more appropriate indicators that enables us to compare the technological performance and technological learning of companies (Acs and Audretsch, 1989; Aspden, 1983; Cantwell and Hodson, 1991; Napolitano and Sirilli, 1990; Patel and Pavitt, 1991 and 1995; Pavitt, 1988). ${ }^{5}$ As such this indicator is particularly relevant for our study of networks of strategic technology alliances, which can be expected to influence the technological learning capabilities of companies. See also Powell and Brantley (1992) who describe patents as 'signals' of technological competencies and learning capabilities of companies in inter-firm networks.

\section{Network measures and variables}

As mentioned in the above, strategic technology alliances between companies are taken as the measure of ties in our analysis. These ties are symmetric and multiple, separate alliances between the same partners are also counted separately to account for repeated ties. Networks of these ties are measured for the complete period of the analysis (1986-1992). The main indicators of network strategy in our analysis are standard network measures, such as density, bridge ties, structural equivalence, and status. ${ }^{6}$ See also Annex I for additional information on other measures.

The variable measuring multiple contacts concerns the number of contacts with the same partners. From a learning perspective, having multiple links to a variety of partners increases the probability that companies develop new capabilities. From a traditional network analysis perspective having multiple links to the same partners is of little relevance if not inefficient. For 
this measure (MULTIPLE CONTACTS), we divide the degree centrality $\left(\mathrm{C}_{\mathrm{D}}\right)$ of a firm by the number of its partners to express this relative redundancy. The degree centrality $\left(C_{D}\right)$ is a rather straightforward measure of centrality, which is equal to the total number of direct links of that particular player to all the other players. Players that are represented by a high degree of centrality are said to be in 'the thick of things' (Freeman, 1979, p. 219).

The maintenance of bridge ties, that overarch structural holes with as little redundancy as possible, is measured by means of two indicators: betweenness centrality $\left(\mathrm{C}_{\mathrm{B}}\right)$ and degree centrality $\left(C_{D}\right)$. The importance of bridge ties as such is measured by the betweenness centrality $\left(C_{B}\right)$. Betweenness refers to the number of times a player is located on the shortest geodesic path between two other players. The expression geodesic path is used to denote the shortest path between two points in the network. If a certain player is directly linked to two other players who are not directly linked to each other, then the first actor is said to be 'between' the other players. In an information network, a company that has a high degree of betweenness centrality has a potential to control the flows of information between those other companies (Freeman, 1979; Knoke and Kuklinski, 1982). From an efficiency perspective, the number of bridge ties is more important than the total number of links that a firm has. Therefore, we divided the betweenness centrality $\left(\mathrm{C}_{\mathrm{B}}\right)$ by the degree centrality $\left(\mathrm{C}_{\mathrm{D}}\right)$ to arrive at a relative measure (BRIDGES).

The structural equivalence of firms measures the degree of interaction with the same players (Lorrain and White, 1971). Firms are referred to as structural equivalent if they have identical ties to all other firms in the network (STRUCTURAL EQUIVALENCE). According to Burt (1992a), the lower the number of structural equivalent firms that a company faces, the more effective a firm's network behaviour. In this paper, we use a standard structural 
equivalence measure of the number of identical contacts (Lorrain and White, 1971). Following Wasserman and Faust (1994) we assume that there is no loss of information by combining the two (or more) structurally equivalent actors into a single subset.

Network status is defined as the degree to which a company has alliances with powerful companies in terms of their network position, indicated by the Bonacich eigenvalue centrality measure $\left(\mathrm{C}_{\mathrm{E}}\right)$ (Bonacich, 1972). In this measure the centrality of each firm is determined by the centrality of the firms to which it is connected (Borgatti et al, 1992). The normalised eigenvector that is used in our study is calculated as the scaled eigenvalue centrality divided by the maximum possible difference. A high score on this variable (NETWORK STATUS) means that a company is associated with a relatively large number of powerful partners in terms of their centrality in the network, which seems of particular importance for an efficiency perspective.

Table 1 presents an overview of the expected relationship between each of these variables regarding network efficiency and the technological performance of companies. In the statistical analysis we expect two efficiency variables (BRIDGES and STRUCTURAL EQUIVALENCE), given the way they are operationalized and measured, to be negatively related to performance seen from an efficiency perspective. ${ }^{7}$ For an efficiency strategy, NETWORK STATUS is expected to be positively related to performance. MULTIPLE CONTACTS is irrelevant from an efficiency perspective, whereas from a learning perspective this variable is expected to be the network-variable that is positively related to performance. From the perspective of a learning strategy, the effects of the other variables are predicted to be statistically irrelevant. 
insert table 1 about here

\section{Control variables}

Apart from these network variables, we expect that the size of companies affects their patent activity. In the classical Schumpeterian argument patent activity of companies, indicating their technological performance, increases more than proportionally with firm size. Main arguments are: growing importance of science-based industries, innovation as a major source of competition and economies of scale and scope. The classical counter-argument is provided by Bain (1956), who stated that small companies are more innovation-efficient, whereas larger firms suffer from 'creative backwardness'. Widely accepted is the view by Scherer (1965 and 1984a) that patent activity of companies tends to rise less than proportionally once a threshold has been passed. Empirical studies by Mansfield (1984) and Mueller (1986) support this view of non-linearity. See also Cohen and Levin (1989) for a review of the literature on the effect of size of companies on their innovative output.

The size of companies is measured by taking the average sector specific (i.e. computer) revenues of companies (SIZE). As we take the natural logarithm of size, we also take into account the diminishing effect of size on patenting activity as suggested by the literature.

The $R \& D$ activity of companies, the ratio of $\mathrm{R} \& \mathrm{D}$ spending on computers to computer revenues, is taken as a second control variable (R\&D INTENSITY). We expect an effect of $\mathrm{R} \& \mathrm{D}$ on patent activity as research efforts will (at least partly) be transformed into patents. Also, internal R\&D is important as it can be seen as 'ticket of admission to an information network' (Mowery and Rosenberg, 1989) and as such it is expected to affect both the network properties 
of companies and their learning through alliances (Mowery and Rosenberg, 1989; Powell and Brantley, 1992).

In the literature, the relation between $R \& D$ and patents has been studied extensively. In Kamien and Schwartz's (1982) well-known survey it is stated that "... without much doubt, on average, a direct relation between innovational effort and innovational output exists" (p. 57). However, it is added that other factors can influence the transformation and the relation may not be linear. In studies by Bound et al (1984), Scherer (1984a) and Hausman, Hall and Griliches (1984) it is mentioned that patenting output decreases gradually with an increase of R\&D expenditures. By using the ratio of $\mathrm{R} \& \mathrm{D}$ expenditures to the logarithm of size, we take this decreasing effect into account.

Finally, given the technological leadership of US companies in the international computer industry, we include a US dummy as a dichotomous control variable.

\section{Data sources}

Data for the size of companies and their R\&D expenditures is taken from the Gartner Group's annual Yardstick word-wide top 100 computer hardware companies. ${ }^{8}$ The Yardstick top 100 worldwide is an authoritative statistical review of the computer industry. Data in the Yardstick is updated annually through surveys and research by Gartner Group consultants and analysts. The Yardstick contains calendar year information, as opposed to information based upon fiscal years, which allows us to make better comparisons between companies.

The data on patents for the dependent variable (technological performance) was taken from the US Patent and Trademark Office database (US Department of Commerce). We took the number of patents that firms applied for in SIC code 357 (computer and office equipment), 
which not only covers computers in a narrow sense but also includes peripheral equipment, storage devices and terminals. Although this US data could imply a bias in favour of US companies and against non-US firms, the group of non-US companies in this study represents a group of innovative and rather large firms which are known to patent world wide. Furthermore, the innovation literature suggests several other reasons to take US patents as an indicator. Frequently mentioned are the importance of the US market, the 'real' patent protection offered by US authorities, the level of technological sophistication of the US market which makes it almost compulsory for non-US companies to file patents in the USA. See Patel and Pavitt (1991) for a discussion on the use of US patent data.

The data on strategic technology alliances is obtained from the MERIT-CATI data bank on cooperative technology agreements. The most important data sources for this databank are a large number of international and specialized trade and technology journals for each sector and many fields of technology. The database contains information on each cooperative agreement and some information on companies participating in these agreements. Cooperative agreements are defined as the establishment of common interests between independent (industrial) partners that are not connected through (majority) ownership. The transfer of technology or the undertaking of joint research is considered as crucial to these arrangements. Strategic technology alliances take the form of contractual agreements (such as R\&D pacts) or equity joint ventures. For the purpose of the present analysis, information is used regarding the industrial sectors and fields of technology and the year of establishment of the strategic technology alliance. Additional information on this data bank can be found in Hagedoorn (1993) and Hagedoorn and Schakenraad (1994), or obtained from the authors. 
Data for the independent variables in the analysis covers a seven years period (19861992) during which the number of annually made alliances was growing at an unprecedented rate (Hagedoorn, 1996). This development led to a large number of alliances forming a population of sufficient size. The population of alliances in the analysis is based on the total number of alliances of companies in the computer industry established during the period 19861992.

For the dependent variable we take its value in 1993. This implies that we introduce a time lag of, on average, four years for joint innovative input, such as joint $R \& D$ projects, to materialize into innovative output, i.e. patents. Research on such time-lags (Scherer, 1984b and Pakes and Griliches, 1984) suggests that on average an invention leads to patents after about two and a half years, although there is substantial variation. If we include the process of R\&D itself and the additional time that joint projects can be expected to take, then an average time lag of four years appears to be a valid estimate.

As companies are the major carriers of technological change in this network environment, the dynamics of the environment do not only reflect market structural changes but also technological changes that come with the entry of new players into the network and the industrial environment. Many of these new players are relatively small and 'unknown' firms or diversified companies that have a major interest in other industries. This particular aspect of a dynamic environment is relevant in the current context as $64 \%$ of the 88 companies in the analysis entered the overall network during the second half of the period (1989-1992). See Annex II for the list of companies.

Finally, there are several reasons why we chose to analyse one particular population of 
companies, instead of comparing different sectors. First, the objective of this exercise is to compare efficiency and learning behaviour under conditions of a dynamic network environment. Second, within one particular network environment we can control for a large number of industry effects such as differences in economies of scale and economies of scope, alternating business cycle effects and differences in the propensity to patent. ${ }^{9}$ Third, by concentrating on one network environment we follow the example of many recent empirical network analyses (Duysters and Vanhaverbeke, 1996; Human and Provan, 1997; Powell et al, 1996; Walker et al, 1997; Zaheer and Zaheer, 1997) that each study a particular sector or network of companies.

\section{RESULTS}

To measure the effect of different kinds of network behaviour we apply standard ordinary least square regression. Table 2 reports means and standard deviations for the variables in the analysis. In order to detect possible multicollinearity we not only analysed the correlation between the variables (see table 3 ) but we also regressed each independent variable on all the other independent variables. ${ }^{10}$ This latter test showed that no significant multicollinearity was detected as none of the other regressions used for checking multicollinearity in the analysis produces $\mathrm{R}^{2}$ s above $0.7 .^{11}$

insert table 2 about here 
Table 4 presents the OLS analysis for this population of computer companies. According to the $\mathrm{F}$ value and the $\mathrm{R}^{2}$ value, the model is significant. All variables that would support an efficiency perspective are insignificant. As predicted, the most important variable from a learning perspective, MULTIPLE CONTACTS, has a positive effect and is highly significant. insert table 4 about here

The control variables (size, R\&D intensity and the dummy for US companies) appear to have no significant impact on the patent intensity of these computer companies. The (insignificant) negative effect of size that was measured appears to be in-line with some research in the neo-Schumpeterian tradition that was mentioned in the above. The same applies to the insignificant effect of R\&D intensity on technological performance. The results for both these variables suggest a possible non-linear relationship between size, R\&D intensity and patent output.

We also undertook several additional analyses. First, we looked at contractual agreements separately to see whether the form of organization of an alliance might have an effect on our findings. This exercise generated similar results as for the general population of strategic technology alliances. As such this is not that surprising as contractual agreements account for over $75 \%$ of these alliances (Hagedoorn, 1996). Given the small number of equity joint ventures in the sample it was not possible to also run the analysis for this particular form of partnering. 
Second, we also weighed the age of the alliances in the analysis, assuming that e.g. seven years old alliances from 1986 might have a smaller effect on the technological performance of companies in 1993 than alliances that were only two or three years old. This correction for the weight of alliances turned out to have no effect. An explanation for this is found in the fact that the growth of newly made alliances during the early nineties was at least twice as high as during the mid-eighties. This growth pattern with a large presence of later alliances dominates any exercise that considers correcting for the age of strategic technology alliances.

\section{DISCUSSION AND CONCLUSIONS}

Our findings suggest a number of important implications for understanding different forms of network-rationality in a dynamic network environment. In such an environment a network rationality based on a learning strategy seems to become important, as indicated by the effect of this strategy on the higher technological performance of companies. A dynamic environment, characterized by market structural changes that accompany technological development, appears to induce companies to learn as much as possible from a number of 'trusted' sources. With this learning strategy, companies do not necessarily maximize their linkages in terms of being most effective in producing results with little waste of effort. Given the unstable environment they are facing, companies seem to concentrate much more on achieving the desired results as such. As for networks of strategic technology alliances, these desired results are given in terms of technological performance, for which learning as much as possible, even through multiplication of contacts, appears to yield positive results. The multiplication of contacts between the same companies will usually take place over a period of a number of years. Therefore, our findings 
also support earlier research that stresses the importance of a history of partnerships between companies for understanding networks, see Gulati (1995a and b).

These findings complement the recent research of Walker, Kogut and Shan (1997) who conclude that contributions such as Burt (1992a) are probably most relevant in the context of analysing networks of standard market transactions. Walker et al (1997) apply the concept of social capital to develop their understanding of durability of embedded networks of cooperating firms that allow for entry of new players. Although there are differences with a learning perspective, the results regarding the importance of both increasing relationships in another dynamic environment (biotechnology) are quite similar to our findings

However, it is also important to note that our analysis does not reject the idea that efficiency behaviour in building a network of strategic technology alliances could still be instrumental for companies if they want to learn from partners in a static environment. ${ }^{12}$ Then, efficiency, in terms of concentrating both on alliances with primary contacts and with companies that have higher network status, while overarching structural holes with as little redundancy as possible, could generate significantly higher performance for companies that follow such a policy. Or to put it differently, it is possible that in a static environment, higher performance of companies will be associated with efficient network positioning, in the sense that there is nonredundancy and higher selectivity in contacts with other companies.

The distinction between efficiency and learning-based behaviour in the context of networking can also be linked to a further refinement of different forms of learning such as exploitative and explorative learning. Exploitative learning is characterized as routinized learning which adds to the existing knowledge and competencies of a firm without changing the 
nature of its activities. This suggests that, if companies build networks in a static context, in which they have accurate information about the existing capabilities of their network linkages, they can add capabilities to their own performance but the improvement will be in line which what could be expected. Hence, an efficiency or exploitative network strategy could be beneficial in a static environment. Exploratory learning or non-routinized learning involves changes in company routines and experimentation with new alternatives (see, e.g. Dodgson, 1993; March, 1991), which, if successful, does change the nature of competencies of companies and increases their innovative performance. In a dynamic environment, with changes in both players and technologies, exploratory learning becomes more important, not only in terms of the endogenous capabilities of companies, but also in terms of learning when the relevance of the knowledge of partners is not clear in advance. Then, dense patterns of interaction with repeated contacts and continuous flows of information as in exploratory learning-based networks start to count.

As far as network status, in terms of existing network power, is concerned, it seems that this aspect of network performance is less relevant in a dynamic environment. From a learning perspective, it can be argued that status derived from existing network positioning is not so germane in a dynamic context. Having repeated ties with a group of companies, including those companies that still have to demonstrate their value, probably has a higher learning potential than linking up to companies that are well established in terms of being connected to other, historically, powerful companies.

Finally, it is obvious that the current analysis has its limitations in terms of the degree to which we can generalise its outcomes. However, the results are quite significant, not only 
statistically, but also because we study a large and important network environment. Future studies of other networks might provide further insight into the rationality that lies behind both efficiency and exploitative forms of network strategies as well as exploratory and learning strategies. The current contribution does already strongly suggests that alternative forms of networking behaviour and network configurations, based on different perceptions of rational behaviour and learning, can generate diverging results in terms of the technological performance of companies. 


\section{REFERENCES}

Acs, Z.J. and D.B. Audretsch, 1989, Patents as a measure of innovative activity, Kyklos, 4, pp. $171-180$

Allen, P.M., 1988, Evolution, innovation and economics, in G. Dosi, C. Freeman, R. Nelson, G. Silverberg and L. Soete, Technical change and economic theory, London, Pinter, pp. 95-120. Andrews, B., 1995, Review of Burt's structural holes - The social structure of competition, in Administrative Science Quarterly, 40, pp. 355-358.

Archibugi, D., 1992, Patenting as an indicator of technological innovation: a review, $\underline{\text { Science }}$ and Public Policy, 6, pp. 357-358.

Arundel, A. and I. Kabla, 1998, What percentage of innovations are patented? Empirical estimates for European firms, Research Policy, 27, pp. 127-141.

Aspden, H., 1983, Patent statistics as a measure of technological vitality, World Patent Information, 5, pp. 170-173.

Bain, J.S., 1956, Barriers to new competition, Cambridge, Harvard University Press.

Barkema, H.G. and F. Vermeulen, 1998, International expansion through start-up or acquisition: a learning perspective, Academy of Management Journal, 41, pp. 7-26.

Bonacich, P., 1972, Factoring and weighting approaches to status scores and clique identification, Journal of Mathematical Sociology, 2, pp. 113-120.

Borgatti, S. P., M.G. Everett and L.C. Freeman, 1992, Ucinet IV Version 1.0, Columbia (SC), Analytic Technologies.

Bound, J., C. Cummins, Z. Griliches, B.H. Hall, and A. Jaffe, 1984, Who does R\&D and who patents?, in Z. Griliches (ed.), R\&D, patents, and productivity, Chicago, University of Chicago 
Press, pp. 21-54.

Burkhardt, M.E. and D.J. Brass, 1990, Changing patterns or patterns of change: the effects of change in technology on social network structure power, Administrative Science Quarterly, 35, pp. 104-127.

Burt, R.S., 1992a, Structural holes - The social structure of competition, Cambridge (MA), Harvard University Press.

Burt, R.S., 1992b, The social structure of competition, in N. Nohria and R.G. Eccles, Networks and organizations, Boston (MA), Harvard Business School Press, pp. 57-91.

Cantwell, J. and C. Hodson, 1991, Global R\&D and UK competitiveness, in M. Casson (ed.), Global research strategy and international competitiveness, Oxford, Blackwell, pp. 133-182.

Ciborra, C., 1991, Alliances as learning experiments: cooperation, competition and change in high-tech industries, in L.K. Mytelka (ed.), Strategic partnerships and the world economy, London, pinter, pp. 51-77.

Cohen, W.M. and R.C. Levin, 1989, Empirical studies of innovation and market structure, in R. Schmalensee and R. Willig, 1989, Handbook of industrial organization, Vol. 2, Amsterdam, Elsevier, pp. 1059-1107.

Cohen, W. and D. Levinthal, 1989, Innovation and learning: the two faces of R\&D, The Economic Journal, 99, pp. 569-596.

Cyert, R.M. and J.G. March, 1963, A behavioral theory of the firm, Englewood Cliffs, PrenticeHall.

Dodgson, M., 1993, Organizational learning: a review of some literatures, $\underline{\text { Organization Studies, }}$ vol. 14, pp. 375-394. 
Dosi, G., C. Freeman, R. Nelson, G. Silverberg and L. Soete, 1988, Technical change and economic theory, London, Pinter Publishers.

Duysters, G., 1996, The dynamics of technical innovation, Cheltenham, Edward Elgar.

Duysters, G. and J. Hagedoorn, 1995, Strategic groups and inter-firm networks in international high-tech industries, Journal of Management Studies, 32, pp .361-381.

Duysters, G. and J. Hagedoorn, 1998, Technological convergence in the IT industry: the role of strategic technology alliances and technological competencies, International Journal of the Economics of Business, 5, pp 355-368.

Duysters, G. and W. Vanhaverbeke, 1996, Strategic interactions in DRAM and RISC technology: a network approach, Scandinavian Journal of Management, 12, pp. 437-461.

Erbe, W., 1962, Gregariousness, group membership, and the flow of information, American Journal of Sociology, 67, pp. 502-516.

Freeman, L.C., 1979, Centrality in social networks, Social Networks, 1, pp. 215-239.

Gartner Group, 1994, Yardstick IT market data, Stamford (CT), Gartner Group.

Gomes-Casseres, B., 1996, The alliance revolution - The new shape of business rivalry, Cambridge (MA), Harvard University Press.

Granovetter, M.S., 1973, The strength of weak ties, American Journal of Sociology, 78, pp. 1360-1380.

Griliches, Z., 1990, Patent statistics as economic indicators: a survey, Journal of Economic Literature, 28, pp. 1661-1697.

Gulati, R., 1995a, Social structure and alliance formation patterns: a longitudinal analysis, Administrative Science Quarterly, 40, pp. 619-652. 
Gulati, R., 1995b, Does familiarity breed trust? The implications of repeated ties for contractual choice in alliances, Academy of Management Journal, 38, pp. 85-112.

Hagedoorn, J., 1989, The dynamic analysis of innovation and diffusion, London, Pinter Publishers.

Hagedoorn, J., 1993, Understanding the rationale of strategic technology partnering: interorganizational modes of cooperation and sectoral differences, Strategic Management Journal, 14, pp. 371-385.

Hagedoorn, J., 1996, Trends and patterns in strategic technology partnering since the early seventies, Review of Industrial Organization, 11, pp. 601-616.

Hagedoorn, J. and J. Schakenraad, 1992, Leading companies and networks of strategic alliances in information technologies, Research Policy, 1992, 21, pp. 163-190.

Hagedoorn, J. and J. Schakenraad, 1994, The effect of strategic technology alliances on company performance, Strategic Management Journal, 15, pp.291-311.

Hausman, J., B.H. Hall and Z. Griliches, 1984, Econometric models for count data with an application to the patents-R\&D relationship, Econometrica, 52, pp. 909-938.

Heide, J.B. and A.S. Miner, 1992, The shadow of the future: effects of anticipated interaction and frequency of contacts on buyer-seller cooperation, Academy of Management Journal, 35, pp. 265-291.

Human, S.H. and K. Provan, 1997, An emergent theory of structure and outcomes in small-firm strategic manufacturing networks, Academy of Management Journal, 40, pp. 368-403.

Kamien, M.I. and N.L. Schwartz, 1982, Market structure and innovation, Cambridge, Cambridge University Press. 
Knoke, D. and J.H. Kuklinski, 1982, Network analysis, London, Sage Publications.

Kogut, B., 1989, The stability of joint ventures: reciprocity and competitive rivalry, Journal of Industrial Economics, 38, pp. 183-193.

Leik, R.L., 1992, New directions for network exchange theory: strategic manipulation of network linkages, Social Networks, 14, pp. 309-323.

Lewis-Beck, M.S., 1993, Regression analysis, London, Sage Publications

Leik, R.L., 1992, New directions for network exchange theory: strategic manipulation of network linkages, Social Networks, 14, pp. 309-323.

Lorrain F. and H.C. White, 1971, Structural equivalence of individuals in social networks, Journal of Mathematical Sociology, 1, pp. 49-80.

Mansfield, E., 1984, R\&D and innovation: Some empirical findings, in Z. Griliches (ed.), R\&D, patents, and productivity, Chicago, University of Chicago Press, pp. 127-148.

Mansfield, E., 1986, Patents and innovation: an empirical study, Management Science, 32, pp. 173-181.

March, J.G., 1991, Exploration and exploitation in organizational learning, Organization Science, vol. 2, pp. 71-87

March, J.G., 1994, The evolution of evolution, in J.A.C. Baum and J.V. Singh, Evolutionary dynamics of organizations, Oxford, Oxford University Press, pp. 39-49.

Mowery, D.C. and N. Rosenberg, 1989, Technology and the pursuit of economic growth, New York, Cambridge University Press

Mowery, D.C., J.E. Oxley and B.S. Silverman, 1997, Strategic alliances and inter-firm knowledge transfer, Strategic Management Journal, 17 (Winter Special Issue), pp. 77-91. 
Mueller, D.C., 1986, The modern corporation - Profits, growth and performance, Brighton, Wheatsheaf Books.

Mytelka, L.K. (ed.), 1991, Strategic partnerships and the world economy, London, Pinter.

Napolitano, G. and G. Sirilli, 1990, The patent system and the exploitation of inventions: results of a statistical survey conducted in Italy, Technovation, 10, pp. 5-16.

Nelson, R.R. and S.G. Winter, 1982, An evolutionary theory of economic change, Cambridge (Mass.), Belknap Press.

Nooteboom, B., H. Berger and N.G. Noorderhaven, 1997, Effects of trust and governance on relational risk, Academy of Management Journal, 40, pp.308-338.

OECD. 1992. Technology and the economy. Paris, OECD.

OECD, 1997, Revision of the high technology sector and product classification, Paris, OECD. Osborn, R.N. and J. Hagedoorn, 1997, The institutionalization and evolutionary dynamics of inter-organizational alliances and networks, Academy of Management Journal, 40, pp. 883-896. Oster, S.M., 1992, Modern competitive analysis, New York, Oxford University Press.

Pakes, A. and Z. Griliches, 1984, Patents and R\&D at the firm level: a first look, in Z. Griliches (ed.), R\&D, patents and productivity, Chicago, The University of Chicago Press, pp. 55-72.

Patel P. and K. Pavitt, 1991, Large firms in the production of the world's technology: An important case of 'non-globalization, Journal of International Business Studies, 22, pp. 1-21. Patel, P. and K. Pavitt, 1995, Divergence in technological development among countries and firms, in J. Hagedoorn (ed.), Technical change and the world economy, Aldershot, Edward Elgar, pp. 147-181.

Pavitt, K., 1988, Uses and abuses of patent statistics, in A.F.J. van Raan, $\underline{\text { Handbook of }}$ 
Quantitative Studies of Science and Technology, Amsterdam, Elsevier.

Philips, A., 1971, Technology and marketstructure, Lexington, Lexington Books.

Powell, W.W., K.W. Koput, L. Smith-Doerr, 1996, Interorganizational collaboration and the locus of innovation: Networks of learning in biotechnology, Administrative Science Quarterly, 41, pp. 116-145.

Powell, W.W. and P. Brantley, 1992, Competitive cooperation in biotechnology: learning through networks, in N. Nohria and R.G. Eccles, Networks and organizations, Boston, Harvard Business School Press, pp. 366-394.

Sahal, D., 1981, Patterns of technological innovation, Reading, Addison-Wesley.

Salancik, G.R., 1995, Wanted: a good network theory of organization, Administrative Science Quarterly, 40, pp. 345-349.

Saxton, T., 1997, The effects of partner and relationship characteristics on alliance outcomes, Academy of Management Journal, 40, pp. 483-498.

Scherer, F.M., 1965, Firm size, market structure, opportunity, and the output of patented innovations, American Economic Review, 15, pp. 1097-1123.

Scherer, F.M., 1984a, Innovation and growth: Schumpeterian perspectives, Cambridge, MIT Press

Scherer, F.M., 1984b, Using linked patent and R\&D data to measure interindustry technology flows, in Z. Griliches (ed.), R\&D, patents and productivity, Chicago, The University of Chicago Press, pp. 417-464.

Silverberg, G. and B. Verspagen, 1994, Learning, innovation and economic growth: a long-run model of industrial dynamics, Industrial and Corporate Change, 3, pp. 199-223. 
Silverberg, G. and B. Verspagen, 1996, From the artificial to the endogenous: modelling evolutionary adaptation and economic growth, in E. Helmstaetter and M. Perlman (eds.), $\underline{\text { Behavioral norms, technological progress, and economic dynamics - Studies in Schumpeterian }}$ economics, Ann Arbor, University of Michigan Press, pp. 331-371.

Simon, H.A., 1956, Rational choice and the structure of the environment, Psychological Review, vol. 63 , pp. $129-138$.

Simon, H.A., 1987, 'Satisficing', in J. Eatwell, M. Millgate, P. Newman (eds.), The new Palgrave: a dictionary of economics, 4, pp. 243-245.

Wade, J., 1996, A community-level analysis of sources and rates of technological variation in the microprocessor market, Academy of Management Journal, 39, pp. 1218-1244.

Walker, G., B. Kogut and W. Shan, 1997, Social capital, structural holes and the formation of an industry network, Organization Science, 8, pp. 109-125.

Wasserman, S and K. Faust, 1994, Social network analysis: methods and applications, Cambridge, Cambridge University Press.

Willer D., 1992, Predicting power in exchange networks: a brief history and introduction to the issues, $\underline{\text { Social networks, }}$ 14, pp. 187-211.

Yamaguchi, K., 1994, The flow of information through social networks: diagonal-free measures of inefficiency and the structural determinants of inefficiency, Social Networks, 16, pp. 57-86. Zaheer, A. and S. Zaheer, 1997, Catching the wave: alertness, responsiveness and market influence in global electronic networks, working paper forthcoming in Management Science. 
Table 1 The expected effect* of network variables on the technological performance of companies from the perspective of efficiency behaviour and learning behaviour in a dynamic environment

\begin{tabular}{|l|l|l|}
\hline VARIABLES & EFFICIENCY & LEARNING \\
\hline MULTIPLE CONTACTS & Irrelevant & $\underline{\text { Positive }}$ \\
\hline BRIDGES & $\underline{\text { Negative }}$ & Irrelevant \\
\hline STRUCTURAL EQUIVALENCE & $\underline{\text { Negative }}$ & Irrelevant \\
\hline NETWORK STATUS & $\underline{\text { Positive }}$ & Irrelevant \\
\hline
\end{tabular}

* negative and positive effects refer primarily to the expected non-normative, statistical relationships, see also note 7 . 
Table 2 Means and standard deviations for variables in the analysis of the effect of network characteristics on the technological performance of companies, $n=88$

\begin{tabular}{|l|r|r|}
\hline VARIABLE & MEAN & $\begin{array}{l}\text { STANDARD } \\
\text { DEVIATION }\end{array}$ \\
\hline Multiple contacts & 0.3711 & 0.8929 \\
\hline Bridges & 0.5010 & 0.3538 \\
\hline Structural & 0.8714 & 0.2970 \\
Equivalence & & \\
\hline Network status & 5.8327 & 12.1543 \\
\hline Size & 13.7028 & 1.3022 \\
\hline US dummy & & \\
\hline R\&D intensity & 0.6591 & 0.4767 \\
\hline
\end{tabular}


Table 3 Pearson correlation coefficients, $n=88$

\begin{tabular}{|c|c|c|c|c|c|c|c|}
\hline & $\begin{array}{l}\text { Multiple } \\
\text { contacts }\end{array}$ & Bridges & $\begin{array}{l}\text { Structural } \\
\text { equivalence }\end{array}$ & Network status & Size & US dummy & R\&D intensity \\
\hline $\begin{array}{l}\text { Multiple } \\
\text { contacts }\end{array}$ & 1.000 & & & & & & \\
\hline Bridges & -0.036 & 1.000 & & & & & \\
\hline $\begin{array}{l}\text { Structural } \\
\text { equivalence }\end{array}$ & -0.066 & 0.170 & 1.000 & & & & \\
\hline Network status & $0.462^{* *}$ & -0.132 & 0.057 & 1.000 & & & \\
\hline Size & $0.234^{*}$ & 0.138 & 0.066 & $0.440^{* * *}$ & 1.000 & & \\
\hline US dummy & -0.161 & -0.023 & -0.072 & -0.026 & $-0.352^{* *}$ & 1.000 & \\
\hline R\&D intensity & $0.295^{* *}$ & -0.167 & -0.071 & $0.228^{*}$ & 0.198 & 0.124 & 1.000 \\
\hline
\end{tabular}

${ }^{*}$ Correlation is significant at the 0.05 level (2-tailed) ${ }^{* *}$ Correlation is significant at the 0.01 level (2-tailed) 
Table 4 The effect of network characteristics on the technological performance of companies in the international computer industry, $n=88$

\begin{tabular}{|l|l|l|}
\hline Variable & Beta & T \\
\hline Constant & & 0.53 \\
\hline Multiple contacts & 0.582 & $3.22 *$ \\
\hline Bridges & -0.050 & -0.31 \\
\hline $\begin{array}{l}\text { Structural } \\
\text { equivalence }\end{array}$ & 0.106 & 0.68 \\
\hline Network status & 0.167 & 0.85 \\
\hline Size & -0.095 & -0.50 \\
\hline US dummy & -0.140 & -0.02 \\
\hline R\&D intensity & -0.004 & -0.81 \\
\hline
\end{tabular}

$$
\begin{aligned}
& * \mathrm{p}<0.01 \\
& \mathrm{R}^{2}=0.47 \quad \text { Adj } \mathrm{R}^{2}=0.31 \quad \text { Std } \mathrm{Er}=0.026 \quad \mathrm{~F}=2.95 \quad \text { Sign. } \mathrm{F}=0.023
\end{aligned}
$$




\section{ANNEX I Brief technical description of standard network measures}

\section{Degree centrality:}

$$
C_{D}(P k)=\sum_{i=1}^{n} a\left(p_{i}, p_{k}\right)
$$

$\mathrm{a}\left(\mathrm{P}_{\mathrm{i}}, \mathrm{P}_{\mathrm{K}}\right)=1$ if $\mathrm{P}_{\mathrm{i}}$ and $\mathrm{P}_{\mathrm{K}}$ are connected directly, and 0 otherwise.

Betweenness centrality:

$$
C_{B}\left(p_{k}\right)=\sum_{l}^{n} \sum_{<j}^{n} \frac{g_{i j}\left(p_{k}\right)}{g_{i j}}
$$

$\mathrm{n}$ represents the number of points in the network, $\mathrm{g}_{\mathrm{ij}}$ represents the number of geodesic paths linking $\mathrm{p}_{\mathrm{i}}$ and $\mathrm{p}_{\mathrm{j}}$ that contain $\mathrm{p}_{\mathrm{k}}$.

\section{Structural equivalence:}

Given an adjacency matrix, or a set of adjacency matrices for different relations, a correlation matrix can be formed by the following procedure. A profile vector is formed for a vertex $\mathrm{i}$ by concatenating the $\mathrm{i}^{\text {th }}$ row in every adjacency matrix. The $\mathrm{i}, \mathrm{j}^{\text {th }}$ element of the correlation matrix is the Pearson correlation coefficient of the profile vectors of $i$ and $j$. This (square, symmetric) matrix is called the first correlation matrix.

The procedure can be performed iteratively on the correlation matrix until convergence takes 
place. Each entry is now 1 or -1 . This matrix is used to split the data into two blocks such that members of the same blocks are positively correlated, members of different blocks are negatively correlated.

CONCOR, a widely applied block modelling algorithm, uses the technique mentioned above to split the initial data into two blocks. Successive splits are then applied to the separate blocks. At each iteration all blocks are submitted to the analysis. However, blocks containing two vertices are not split. Consequently n-partitions of the binary tree can produce up to $2 \mathrm{n}$ blocks (see Borgatti et al, 1992).

\section{Network status indicated by a normalized eigenvector:}

Given an adjacency matrix A, the centrality of vertex $\mathrm{i}$ (denoted ci) is given by $\mathrm{ci}=\alpha \Sigma \mathrm{Aijcj}$ where $\alpha$ is a parameter. The centrality of each vertex is therefore determined by the centrality of the vertices it is connected to. The parameter $\alpha$ is required to give the equations a non-trivial solution and is therefore the reciprocal of an eigenvalue. The normalized eigenvector centrality is the scaled eigenvector centrality divided by the maximum difference, expressed as a percentage (see Borgatti et al, 1992). 
ANNEX II List of 88 companies in the network analysis of the international computer industry

\begin{tabular}{|c|c|c|}
\hline $\begin{array}{l}\text { 3Com } \\
\text { Acer Corp.* } \\
\text { Alps Electric } \\
\text { Amdahl } \\
\text { Apple* } \\
\text { AST Research* } \\
\text { AT\&T* } \\
\text { BASF - Comparex } \\
\text { Canon } \\
\text { Cisco Systems } \\
\text { Commodore } \\
\text { Compaq* } \\
\text { CompuAdd } \\
\text { Computer Vision } \\
\text { Conner } \\
\text { Control Data Corp. } \\
\text { Cray Research* } \\
\text { Data General } \\
\text { Dell } \\
\text { Digital Equipment Co.* } \\
\text { Escom } \\
\text { Fujitsu* } \\
\text { Groupe Bull* } \\
\text { Hewlett-Packard* } \\
\text { Hitachi* } \\
\text { IBM* } \\
\text { Intel* } \\
\text { Intergraph } \\
\text { Kaufhof }\end{array}$ & $\begin{array}{l}\text { Lexmark } \\
\text { Lockheed } \\
\text { Mannesman } \\
\text { Matsushita* } \\
\text { Maxtor } \\
\text { Memorex-Telex* } \\
\text { Mitac } \\
\text { Mitsubishi } \\
\text { Motorola* } \\
\text { NEC* } \\
\text { Nihon Unisys* } \\
\text { Northern Telecom } \\
\text { NTT } \\
\text { Oki } \\
\text { Olivetti* } \\
\text { Philips* } \\
\text { Quantum } \\
\text { Racal } \\
\text { Ricoh } \\
\text { Seagate } \\
\text { Seiko Epson } \\
\text { Siemens* } \\
\text { Silicon Graphics* } \\
\text { Sony* } \\
\text { Storage } \\
\text { Stratus* } \\
\text { Sun Microsystems* } \\
\text { Tandem* } \\
\text { Tandy* }\end{array}$ & $\begin{array}{l}\text { Texas Instruments* } \\
\text { Toshiba* } \\
\text { Unisys } \\
\text { Wang } \\
\text { Wyse* } \\
\text { Xerox } \\
\text { Quantum } \\
\text { Gateway } \\
\text { Packard-Bell } \\
\text { EMC } \\
\text { Synoptics } \\
\text { Cabletron } \\
\text { Micropolis } \\
\text { Tektronix* } \\
\text { Cadence } \\
\text { Sequent* } \\
\text { Mentor Graphics } \\
\text { National Computer Systems } \\
\text { QMS } \\
\text { Exabyte } \\
\text { Telxon } \\
\text { Gerber Scientific } \\
\text { Digital Communications } \\
\text { Recognition Equipment } \\
\text { Banctec } \\
\text { NET } \\
\text { Genicom } \\
\text { Zeos } \\
\text { Network Systems } \\
\text { General DataComm }\end{array}$ \\
\hline
\end{tabular}

* marks a company that was already active in the network during the period 1986-1988 
1.This debate about the rationale of networks, the role of information and their effect on performance clearly fits in the tradition of social network analysis influenced by the seminal work of Granovetter (1973) where 'weak ties' in networks serve as bridges that can help to transfer information from one group of players to another.

2.As in economic theory, there is a recent increase in the number of advanced, theoretical studies that focus on the role of incomplete information (Willer, 1992).

3.The technical implications in terms of the variables for network analysis are discussed in the section on 'methodology and data'.

4.This learning approach shares a number of aspects of its criticism of efficiency assumptions with the behavioural theory (Simon, 1956 and 1987; Cyert and March, 1963) and evolutionary economics (Nelson and Winter, 1982). A central element in these alternative approaches is the concept of 'bounded rationality' with companies demonstrating a satisficing behaviour under conditions of imperfect knowledge. Also, the attention for topics such as routinized behaviour and learning opposes more orthodox approaches that explain behaviour of companies in the light of efficiency and rational choices that lead to an optimization of decision rules.

5.It is important to note that the dependent variable measures the technological capabilities and performance of individual companies that are affected, amongst other things, by strategic technology alliances. This indicator does not measure joint patenting activities as it reflects the technological performance of each individual company in the population.

6.In other words, we stay as close as possible to conventional network analysis.

7.It should be clear that this negative relationship is due to the specifics of the measurement of these variables. The assumed negative relationship does not indicate a normative appreciation. For reasons of clarity of arrangement we designed these variables in such a way that for an efficiency strategy the expected sign in the analysis would be negative due to the conversion of values.

8.The Gartner group (1994) estimates that their sample of the leading 100 computer companies account for over $90 \%$ of the worldwide market. The firms in our sample cover more than $90 \%$ of the revenues presented in the Gartner Group sample. This implies that our sample accounts for more than $80 \%$ of the total computer industry.

9. In particular the differences in propensity to patent is crucial. If we were to undertake an analysis in which we would compare different networking strategies in e.g. a dynamic and a static environment, the comparison using patents as an indicator of technological performance would be troublesome. In the MERIT-CATI data set sectors such as the steel industry and the auto industry would qualify as mature, static environments with a large enough number of strategic technology 
alliances with a stable number of partnering companies. However, previous research (e.g. Arundel and Kabla, 1998 and Mansfield, 1986) indicates that patents are poor indicators of technological performance in these industries, making the exercise rather useless.

10.This method is often described as the most preferred method of assessing multicollinearity (see Lewis-Beck, 1993). The advantage over the frequent practice of examining bivariate correlations among the independent variables is that it takes into account the relationship between all independent variables and an independent variable. As noted in Lewis-Beck (1993, p. 52) “... (i)t is possible, for instance, to find no large bivariate correlations, although one of the independent variables is a nearly perfect linear combination of the remaining independent variables ...".

11. $\mathrm{R}^{2} \mathrm{~S}$ close to 1.0 are considered to reveal a high degree of multicollinearity (Lewis-Beck, 1993).

12.As mentioned in note 9 , there are some serious methodological problems in comparing network strategies and technological performance in a dynamic network environment with a static environment, using the same measure for technological performance. Our current analysis is limited to one network environment and we can only speculate about the possible relevance of efficiency behaviour in a static network environment. 